\title{
As dinâmicas das redes no campo do turismo: \\ uma aposta na diversidade
}

The dynamics of networks in the field of tourism: a bet on diversity

Dinámica de la red en el campo del turismo: una apuesta en la diversidad http://dx.doi.org/10.18472/cvt.16n3.2016.1181

Rafael Ângelo Fortunato < fortrafa@hotmail.com >

Instituto de Geografia da Universidade Estadual do Rio de Janeiro (UERJ), Rio de Janeiro, RJ, Brasil.

Marília Lima Garcez〈marilia.garcez@hotmail.com >

Instituto de Geografia da Universidade Estadual do Rio de Janeiro (UERJ), Rio de Janeiro, RJ, Brasil.

CRONOLOGIA DO PROCESSO EDITORIAL

Recebimento do artigo: 17-nov-2015

Aceite: 17 -jul-2016

FORMATO PARA CITAÇÃO DESTE ARTIGO

FORTUNATO, R. A.; GARCEZ, M. L. As dinâmicas das redes no campo do turismo: uma aposta na diversidade. Caderno Virtual de Turismo. Rio de Janeiro, v. 16, n. 3, p. 191-202, dez. 2016.

REALIZAÇÃO

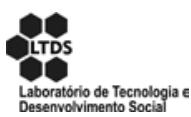

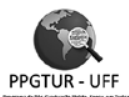

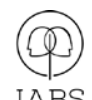

APOIO INSTITUCIONAL

EDIÇÃO

PATROCÍNIO

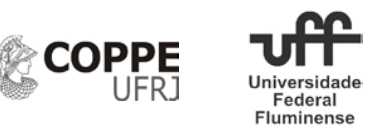

IPDITR 


\section{RESUMO}

Este artigo pretende estabelecer reflexões sobre as dinâmicas e a importância das formações de redes para organização e promoção da atividade turística. Estudamos a rede Brasilidade Solidária. O objetivo da rede é divulgar ações que se aproximem do conceito de turismo solidário e contribuir com a gestão da atividade. Trabalhamos com a observação participante e com a pesquisa-ação. Atuamos em todos os processos de desenvolvimento do turismo nas localidades (reuniões, conhecimento dos territórios e produção de novos roteiros). Os dados de pesquisa foram organizados em seis categorias de análises: disputas e divergências; indicações e não linearidades; rede e política; redes sociais virtuais; rede e visibilidade e densidade da rede. Consideramos que a formação de redes é fundamental para o desenvolvimento da atividade turística, mas que a sua dinâmica precisa ser pensada de forma crítica e requer uma abordagem complexa capaz de superar os desafios e contribuir para o desenvolvimento local.

Palavras-chave: Turismo de Base Comunitária. Redes. Complexidade.

\section{ABSTRACT}

This article aims to establish reflections on the dynamics and the importance of training networks for the organization and promotion of tourism. We study the rede Brasilidade Solidária. The network's objective is to promote actions that align themselves with the solidarity concept of tourism and contribute to the management of the activity. We work with the participant observation and action research. We operate in all tourism development processes in places (meetings, knowledge of the territory and production of new routes). The research data were organized into six categories of analysis: disputes and disagreements; indications and nonlinearities; network and policy; virtual social networks, and network visibility and network density. We believe that the formation of networks is essential for the development of tourism, but their momentum needs to be thought critically and requires a complex approach that can overcome challenges and contribute to local development.

Keywords: Community Based Tourism. Networks. Complexity.

\section{RESUMEN}

Este artículo tiene como objetivo establecer reflexiones sobre la dinámica y la importancia de las redes de formación a la organización y promoción del turismo. Estudiamos la rede Brasilidade Solidária. El objetivo de la red es promover acciones que se alinean con el concepto de solidaridad de turismo y contribuyen a la gestión de la actividad. Trabajamos con la observación participante y la investigación-acción. Estamos presentes en todos los procesos de desarrollo turístico en lugares (reuniones, conocimiento del territorio y la producción de nuevas rutas). Los datos de la investigación fueron organizados en seis categorías de análisis: conflictos y desacuerdos; indicaciones y no lineales; la red y la política; redes sociales virtuales y visibilidad de la red y la densidad de la red. Creemos que la formación de redes es esencial para el desarrollo del turismo, pero su impulso necesita ser pensada de manera crítica y requiere un enfoque complejo que puede superar los desafíos y contribuir al desarrollo local.

Palabras clave: Turismo de base comunitaria. Redes. Complejidad. 


\section{Introdução}

O tema das redes está cada vez mais presente na contemporaneidade e ele aparece nos mais diversos campos do saber popular e científico. Fala-se em redes sociais, redes de computadores, redes de televisão, redes de eletricidade e redes de transporte. Uma das ideias por trás da palavra "rede" está mais relacionada à questão da infraestrutura, outro aspecto se relaciona mais com uma abstração, um conceito, uma ideia, políticas, inclusive as relações familiares podem ser pensadas utilizando o modelo de redes. Para Barnes (2010, p. 173), a "rede social pode ser útil no exame de vários tipos de situações sociais".

A palavra "rede" é utilizada, também, para referir-se a tudo que é entrelaçado, assim como: redes de pesca e redes para dormir. Apesar dos múltiplos significados atrelados a essa palavra, recentemente, está crescendo o uso dessa nomenclatura para pensar em uma nova forma de planejamento e organização do turismo denominada de "redes de turismo".

Tendo em vista esse novo cenário, decidimos refletir sobre as dinâmicas, os desafios e as potencialidades para formação de redes no turismo. Para isso, analisamos o trabalho da rede Brasilidade Solidária, que atua no estado do Rio de Janeiro há dois anos. A atuação da rede ocorre, predominantemente, com a aplicação de cursos de extensão universitária e reuniões para o desenvolvimento de novos produtos turísticos a partir do conceito de turismo solidário (FORTUNATO; NEFFA, 2014).

A pesquisa está em andamento e não tem prazo para terminar, pois trabalhamos com foco na pesquisa-ação e na observação participante para tentar entender um conceito abstrato e seu funcionamento nos processos de trabalho. Utilizamos, também, o método etnográfico, visto que as descrições dos casos ocorridos durante as reuniões e os trabalhos da rede revelam as dinâmicas das redes.

A pesquisa-ação está ocorrendo em três localidades do Rio de Janeiro (Rocinha, Barra de Guaratiba, Morro do Borel) e três localidades em Teresópolis (Santa Rita, Caleme e Granja Guarani). O bairro dos Três Picos, em Nova Friburgo, também já recebeu uma versão do curso e completa os casos influenciados pela rede. $\mathrm{O}$ artigo não irá se concentrar na apresentação de cada um dos casos de modo específico. Nosso foco está no funcionamento de um conceito que perpassa por todas as localidades mencionadas e podem ocorrer nos mais diversos casos, tendo, inclusive, desdobramentos nas redes sociais virtuais.

Para apresentação desse tema, considerado atual e de grande relevância para o desenvolvimento do turismo no Brasil, apresentamos no segundo item algumas considerações sobre as redes e as redes no campo do turismo e, no terceiro item, destacamos os desafios e as oportunidades desse modelo para o planejamento da atividade turística. Vale ressaltar que o turismo é fundamentalmente uma atividade que envolve redes, sua comercialização e estruturação dependem de diversos setores econômicos para funcionar, no entanto, o foco deste trabalho está na criação de novas redes de gestão e comercialização da atividade, que não estão posicionadas nas grandes redes de distribuição responsáveis por operar o turismo de massa.

\section{Redes no campo do turismo}

Para falarmos da cooperação e criação de redes precisamos entender as relações abstratas que existem entre as pessoas. Para Elias (1994), no seu livro "A sociedade dos indivíduos", a sociedade pode ser pensada em termos de uma rede e está "em constante movimento, como um tecer e destecer ininterrupto das 
ligações. É assim que efetivamente cresce o indivíduo, partindo de uma rede de pessoas que existiam antes dele para uma rede que ele ajuda a formar" (ELIAS, 1994, p. 35).

Cada indivíduo, ao estabelecer relações, participa de algo intangível, mas, em muitos casos, produzem materializações que se expressam na produção do espaço. O conceito de rede é complexo e aplicável a todos os ramos da atividade humana e, por isso, possui diferentes significados. Para Musso (2004), a rede é onipresente e onipotente em todas as disciplinas. Em seu texto "Filosofia da Rede", o autor afirma que a rede é uma ligação entre membros que constituem uma unidade.

A proposta da organização em rede aparece com força em vários aspectos da vida em sociedades, assim como nas relações entre parentes. A família pode ser entendida como uma estrutura que se organiza em rede, pois os indivíduos encontram no convívio elementos que garantem uma vida significativa. Por meio da busca de relações significativas formamos redes de amigos, de times de futebol, de amigos, de instituições, etc. Todos esses grupos podem ser interpretados como uma estrutura em redes.

Uma das principais características da rede é sua capacidade de criar momentos significativos para os indivíduos que a compõem, criam-se, portanto, solidariedade entre iguais. Uma crítica deve-se ao fato de que solidariedade entre os iguais, entre pessoas que participam de um grupo de reconhecimento recíproco, é uma atitude mais simples do que nutrir um nível de solidariedade suficiente para lidar com redes de significados diferentes.

Viajando desde a mitologia com a tecelagem e o labirinto, passando pela antiguidade, com a medicina de Hipócrates, Musso (2000) apresenta várias metáforas para explicar o conceito de redes e, com base em Castells, define a rede como um conjunto de nós interconectados, na qual cada nó é o ponto no qual uma curva se entrecorta e cada nó é um ponto de ligação para que as curvas existam.

Castells (1999, p. 02) faz referência à sociedade em rede e destaca que
O resultado foi a descoberta de uma nova estrutura social que estava se formando, que conceituei como sociedade em rede por ser constituída por redes em todas as dimensões fundamentais da organização e da prática social. Além disso, embora as redes sejam uma antiga forma de organização social na experiência humana, as tecnologias digitais de formação de redes, características da Era da Informação, alimentaram as redes sociais e organizacionais de for- mação de redes quanto à gestão da complexidade de redes acima de certa dimensão.

As redes são um meio através do qual se desenvolvem e se manifestam os diferentes tipos de fluxos, conforme o tipo de rede e seus nós e transformam as relações socioespaciais e territoriais, por isso, apresentam grande complexidade.

A complexidade, por sua vez, é caracterizada por relações não lineares. Trabalhamos, portanto, com a ideia de que as relações das redes, por exemplo, ocorrem de modo não linear, pois não é possível determinar exatamente qual o próximo nó que irá se formar devido às múltiplas variáveis existentes nesse processo. Para Tomaél (2005), o conceito de rede é uma estrutura não linear, descentralizada, flexível, dinâmica, sem limites definidos e auto-organizável, que se estabelece por relações horizontais de cooperação.

Musso (2004) compara o corpo humano a uma teia de aranha, dizendo que é como uma rede que se forma, cresce, se estende e lança milhares de fios imperceptíveis. Os fios estão em toda parte do corpo, não havendo um ponto único. Essa comparação remete à rede controlada por seu centro e submetendo a periferia, ou seja, basta se deslocar do centro à periferia como a aranha sobre a teia. 
Sain-Simon estabelecera que, quanto mais um corpo é organizado, mais ele tem ação sobre seu ambiente. Por analogia, ele afirma que, quanto mais uma sociedade está organizada, melhor ela é organizada e mais ação ela produz sobre a natureza: quanto mais sua organização interna é feita de redes, mais ela as estabelece sobre o território (MUSSO, 2004, p.15).

De acordo com Tomaél (2005), as redes estão em qualquer tipo de relacionamento e estão ligadas à natureza humana. Influenciam na organização dos espaços e nas relações de poder para determinar características importantes do território.

Se pensarmos nos relacionamentos que possuímos, percebemos como indivíduos levam-nos a outros indivíduos; fatores ou interesses levam-nos a outros indivíduos; e indivíduos levam-nos a interesses, geralmente, em comum. Nós construímos nossas próprias redes; nossos círculos pessoal e profissional comprovam que fatores ou interesses nos conectam a outras pessoas. Edgar Morin, em seu vídeo "A complexidade e Eu", do canal do YouTube: Fronteiras do Pensamento, afirma que existem três aspectos para se tornar um indivíduo completo: o primeiro é o Eu da subjetividade, o egocentrismo, que se preocupa apenas com o interesse pessoal; o segundo é um antagonismo ao primeiro $\mathrm{Eu}$, pois a necessidade de se envolver com o próximo aparece, o indivíduo passa de "eu" para "nós"; e o terceiro marca essa transição, liga o eu ao nós, unindo os indivíduos, transformando em um todo que podemos chamar de sociedade, como o filósofo afirma nesse mesmo vídeo: "não somente os indivíduos estão na sociedade, mas a sociedade está no interior deles. Não somente os indivíduos estão no espaço, mas o espaço está no interior deles".

As relações no interior de uma rede podem ser pensadas de forma analítica, temos, portanto, redes nas quais as relações entre os participantes podem variar em seu grau de intensidade. Geralmente, quando o grau de intensidade é elevado, temos um "padrão de regulação" dos grupos muito bem definido. Em redes com menos regulação, ou seja, mais abertas, as relações ocorrem de maneira mais informal e não há nenhum tipo de obrigação mútua, apenas relações de confiança marcadas por interesses comuns. Reconhecemos que essa demarcação da intensidade das relações faz parte de uma concepção subjetiva, pois alguns indivíduos estão mais propícios a se dedicar à manutenção dos nós do que outros e isso é muito difícil de se medir, pelo menos antes da rede se consolidar.

Martim Buber em seu livro "Eu-Tu", afirma que a palavra "eu" só faz sentido quando acompanhada da palavra "tu”. Tal concepção marca certa disposição dos indivíduos para viver em redes, em sociedade. Elias (1994), na mesma direção de Morin e Buber, destaca que cada pessoa só é capaz de dizer "eu” se e porque pode, ao mesmo tempo, dizer "nós". Até mesmo a ideia "eu sou", e mais ainda a ideia "eu penso", "pressupõe a existência de outras pessoas e um convívio com elas" (ELIAS, 1994, p. 57).

A proposta das redes está diretamente relacionada à questão da formação de grupos que compartilham, minimamente, ideologias e políticas. No entanto, tais grupos, na visão de Latour (2012, p. 55), "não são coisas silenciosas, mas o produto provisório de um rumor constante feito por milhões de vozes contraditórias sobre o que vem a ser um grupo e quem pertence a ele". Para Latour (2012, p. 49), "não há grupos, apenas formação de grupo". Tal abordagem retira da proposta de formação de redes os aspectos ingênuos de que a formação de redes é a solução para todos os nossos problemas.

Assim como a ideia de comunidade, a rede é um ideal a ser alcançado e não algo concreto, preexistente, romantizado. Os "nós" das redes se fortalecem mediante atividades de interesse mútuo e reciprocidade. A solidariedade é o elo que unem pessoas para prestar serviços de qualidade, quando pensamos, por exemplo, nas experiências de produção e consumo no campo do turismo. 
Dessa maneira é possível verificarmos que a rede gera abertura de novos caminhos. A rede nos permite também ultrapassar barreiras e limites à comunicação entre os continentes. Ela consegue unir povos através de sistemas de rápido e fácil acesso.

A rede permite a comunicação, a comunhão e a democratização pela circulação igualitária da informação e do conhecimento. A redução geográfica das distâncias físicas por intermédio das vias de comunicação significa redução das distâncias sociais, tem-se, portanto, uma chance de construirmos relações mais democráticas e significativas. Fato que afeta diretamente o trabalho de planejamento da atividade turística.

Em 2007, o Ministério do Turismo lançou, com o Plano Nacional de Turismo (PNT 2007-2010), o Programa de Regionalização do Turismo: Roteiros do Brasil (PRT 2007) com diversos cadernos, como "Promoção e apoio à Comercialização do Turismo", e um deles a temática era "Formação de Redes" para descentralização dos roteiros turísticos visando à inclusão social, redistribuição dos lucros e fortalecimento de territórios.

Esse documento apresenta o conceito de rede da seguinte forma:

A organização em Rede tem enorme poder de promover a divulgação de informações e a troca de experiências de forma descentralizada. Essa estrutura e sua forma de organização induzem à colaboração, à cooperação, ao trabalho conjunto, à gestão compartilhada e à ação autônoma individual integrada a uma visão coletiva. [...] O processo se apoia justamente nessa propriedade especial das Redes, que é o fortalecimento das articulações. A aproximação e a troca de conhecimento entre os participantes fortalecem a ação local/regional, transformando, assim, uma iniciativa localizada numa prática disseminada, que se espalha para outros lugares, e cujos resultados ultrapassam os limites geográficos de um município, região, estado, ou país." (BRASIL, p. 13)

O documento mostra como a descentralização pode ser uma solução para os impactos negativos que o turismo gera em destinos massificados, por exemplo. A disseminação da proposta seria entre as redes de cooperação de cada destino. Com o objetivo de "promover e apoiar a construção de relações e parcerias entre os diversos agentes envolvidos com a regionalização do turismo no Brasil, por meio da troca de experiências e informações, e de modo a contribuir para o desenvolvimento ordenado da atividade turística do país", o PRT 2007 - Formação de redes, tentaria promover a conectividade, a criação de parcerias e a troca de informação.

Embora os resultados do PRT 2007 não tenham sido divulgados, talvez por falta de monitoramento ou transparência, em 2013 o Ministério do Turismo divulgou as diretrizes do Programa de Regionalização do Turismo 2013-2016, com foco no monitoramento e descentralização dos destinos turísticos, mas com mais clareza sobre as responsabilidades do governo em âmbitos nacionais, estaduais e municipais.

A ideia de regionalizar com formação de redes é fundamental para o Brasil, país multicultural, contudo, sabemos das dificuldades e barreiras que o turismo sofre por falta de planejamento e falhas na gestão. No entanto, a disseminação dessa ideia pode induzir pessoas a formarem suas próprias redes, consolidando seus próprios territórios.

A necessidade, a busca e o uso da informação fazem com que a rede social seja um importante recurso profissional e pessoal, pois as redes "são virtuais, mas também reais, são técnicas, mas também sociais, portanto, são por vezes estáveis, mas também dinâmicas” (ACIOLI, 2007, p. 23), sendo

influenciada pelo seu contexto e esse por ela. [...] A interação constante ocasiona mudanças estruturais e, em relação às interações em que a troca é a informação, a mudança estrutural que pode ser percebida é a do conhecimento, maior será nosso estoque de informação, e é esse o poliedro de significados que inserimos as redes sociais. (TOMAÉL, 2005, p. 15) 
As redes são formas de unir objetivos comuns por meio de pequenos elos. O reconhecimento da importância das redes é um agente facilitador para compreensão dos processos de mobilização, como também dos "caminhos" percorridos pelas informações desses movimentos. Redes consolidadas geram autovalorização e fazem com que os conhecimentos contribuam para o desenvolvimento da atividade turística.

\section{As dinâmicas das redes no campo do turismo}

Nesse item decidimos enumerar quais as potencialidades e dificuldades do trabalho em redes. Focando nas dinâmicas e transformações da rede Brasilidade Solidária, começamos analisando o desejo dos indivíduos de serem reconhecidos como parte do grupo, mas, ao mesmo tempo, de serem reconhecidos enquanto sujeitos individuais. Da arte de combinar esses dois elementos depende o sucesso de uma rede.

\section{- Disputas e divergências}

Em um dos casos trabalhados pela rede constatamos problemas devido ao uso ou não de logomarcas em convites para realização de mutirões. Todos queriam estar presentes, mesmo aqueles que pouco se envolveram na atividade. A rede, de alguma forma, tornou-se uma vitrine para instituições e projetos e provocou disputas entre seus membros.

Constatamos certa concorrência para saber quem indicaria as melhores diretrizes a serem seguidas nos trabalhos dos mutirões. Realizamos quatro mutirões, três no "Mirante da Colina" (importante ponto turístico do município de Teresópolis), no qual promovemos uma revitalização (limpeza, pintura e plantio) e um na Praça Taumaturgo, com plantio de hortaliças, também em Teresópolis. Pessoas que em algum ponto conversam e ajudam a compor uma rede, acabam divergindo em suas posições políticas, principalmente quando algumas delas ligam-se aos poderes constituídos, tanto econômicos quanto políticos. Gera-se um conflito de interesse.

Com o passar do tempo houve uma diminuição na capacidade de mobilização do grupo que participou dos mutirões. Assim como propõe Mafessoli (1998), junção e dispersão fazem parte da configuração atual dos movimentos sociais. Nesse ponto dialogamos também com Bauman (2007), quando apresenta a categoria da "liquidez" para pensar as relações sociais no mundo contemporâneo.

Em se tratando dos mutirões, o fator midiático teve papel decisivo na coesão ou dissolução do grupo, vejamos alguns fatos: no segundo encontro dois veículos de comunicação do município de Teresópolis fizeram a cobertura e, por esse motivo, no terceiro encontro as ações ganharam uma adesão maior de entidades organizadas, mostrando uma capacidade de crescimento. Por outro lado, a exibição na mídia local promoveu certo grau de estranhamento entre os participantes da ação, pois alguns acusavam que determinadas pessoas estavam querendo "se aparecer" mais do que outras.

Devido à grande exposição na mídia local, constatamos um grande risco dos trabalhos da rede serem apropriados indevidamente por partidos políticos ou por pessoas que pretendem candidatar-se a algum cargo político. 


\section{- Indicações e não linearidades}

Outro ponto que merece destaque é a indicação de referências, pois dela depende o crescimento da rede, no caso da rede Brasilidade Solidária esse é o principal mecanismo para o aumento de sua influência. Todas as ações da rede ocorrem a partir da indicação. Receber uma indicação é fundamental para que o processo de desenvolvimento turístico tenha continuidade. O trabalho torna-se muito mais eficaz quando ocorre uma indicação. O processo ganha maior credibilidade no território. Existe uma grande diferença entre ser indicado e oferecer os serviços.

Um fato interessante é que, em alguns casos, as pessoas que fazem a indicação, ou seja, que dão início à relação com a rede, saem de cena, deixam de estar à frente das negociações, das diretrizes tomadas para o desenvolvimento do turismo. Constatamos, portanto, que a rede está inserida em um campo de múltiplas possibilidades e que a tentativa de um controle excessivo acaba comprometendo sua espontaneidade, sua não linearidade e imprevisibilidade. Trabalhar em redes é trabalhar com o imprevisível.

\section{- Rede e Política}

Trabalhar em rede é trabalhar no campo da política, visto isso, torna-se difícil pensar em uma rede muito grande, pois uma rede muito grande acabaria minando a própria força que a criou, sua capacidade de pensar com autonomia e inovação; redes muito grandes correm o risco de eliminar a diversidade e pasteurizar o conhecimento.

As pequenas redes formam elos de ligação entre ideias, fato que garante a autonomia de uma rede, bem como sua originalidade, além do reconhecimento advindo do reconhecimento recíproco, afinal, a proposta filosófica das redes está baseada nos valores da solidariedade, se não for dessa forma, talvez não faça sentido utilizar o termo "redes" para se referir a uma organização da sociedade, pois todas as organizações humanas poderiam utilizar tais nomenclaturas.

Nesse ponto faremos uma crítica à execução da proposta de formação de redes por meio dos entes federativos brasileiros, que, em alguns casos, atuam de forma centralizadora. São propostas novas redes, mas elas se fecham e apresentam dificuldades para formação de redes com diversas instituições importantes, pois trabalham com o pressuposto de redes nas quais os participantes precisam se submeter a critérios muito rigorosos, em vez do reconhecimento e aproveitamento dos trabalhos de redes menores. Nesse cenário, ocorrem trabalhos sobrepostos. Os órgãos públicos precisam mapear as experiências de redes, dar visibilidade para elas e não apenas fomentar uma rede e dar subsídios para que elas cresçam indiscriminadamente.

\section{- Redes sociais virtuais}

As redes sociais virtuais são essenciais, tanto para organização e gestão da atividade turística quanto para sua comercialização. Atualmente a rede Brasilidade Solidária influencia dois grupos nas redes sociais virtuais. O primeiro, denominamos de "Turismo solidário em Barra de Guaratiba". Esse grupo conta com 89 membros. 
Iniciamos os trabalhos em Barra de Guaratiba e Pedra de Guaratiba, a partir de um curso de extensão universitária da UERJ e da realização de um documentário etnográfico denominado "Guaratiba Solidária" (https://www.youtube.com/watch?v=pSg6eedujfQ\&index=2\&list=PLAFB_IfpPfb9yjpN2_m_etYEcyDAbrwvn ). Foram realizadas diversas reuniões e atualmente produzimos um livro de receitas com bases antropológicas na região.

A formação de redes procura ser potencializada por meio da tentativa de dar visibilidade para pessoas que tendem a ter suas vozes silenciadas pelo aparato de comunicação hegemônico, e as redes sociais virtuais são imprescindíveis para que isso ocorra.

O segundo grupo nas redes sociais virtuais denominamos de "Turismo solidário em Teresópolis" e possui 153 membros. O trabalho em Teresópolis-RJ vem sendo concretizado depois da realização de um curso de extensão universitária no município.

Atualmente trabalhamos com o roteiro "Turismo solidário em Santa Rita", que está sendo promovido por um grupo que concluiu o curso. O roteiro demonstra a força do trabalho organizado em rede, pois sua concretização envolve uma grande trama de variáveis, como, por exemplo: a preparação dos sítios que vendem produtos orgânicos, a preparação do sitiante para receber os turistas, os monitores que precisam captar os visitantes, os processos para garantir um transporte adequado, a qualidade das informações transmitidas e os pontos a serem visitados. Essas características do produto fazem dele um agregador de diversos tipos de saberes e pessoas, temos, portanto, na formação de redes as possibilidades para enriquecer cada vez mais os produtos, pois à medida que a troca de informações ocorre, tanto entre os proponentes do turismo, como entre eles e os turistas, o capital simbólico da atividade turística aumenta gradativamente.

\section{- Rede e visibilidade}

O trabalho de Santa Rita mostra as potencialidades promovidas pela rede no sentido de dar visibilidade às ações e gerar frutos até então inimagináveis antes dos encontros pautados no reconhecimento recíproco.

Depois de ter reclamado da dificuldade de escoar sua produção, um proprietário, que recebe visitantes em seu sítio por meio do roteiro "Turismo Solidário em Santa Rita", começou a fazer suas entregas às quartas-feiras para um grupo de compras coletivas formado por pessoas que conheceram a horta. Novamente vimos um novo elo se formando. Constatamos, nesse fato, que o trabalho em redes, no viés do turismo solidário, ajudou os negócios sustentáveis a ganharem maior visibilidade.

O trabalho no Morro do Borel demonstra como as redes têm um papel importante para a promoção do turismo nas favelas cariocas, a partir do envolvimento dos moradores locais, e ilustra, também, os processos não lineares e as dinâmicas de formação de redes.

O trabalho da rede Brasilidade Solidária no Borel começa com a iniciativa de uma moradora de acompanhar nosso trabalho no Complexo do Alemão (primeiro caso de turismo influenciado pela rede). Depois desse dia, o vínculo com a moradora se fortaleceu e fizemos uma visita para (re)conhecermos as potencialidades turísticas do Morro do Borel. Decidimos realizar um curso de extensão na localidade. Formamos nove moradores e eles deram início ao roteiro "Borel Tour: tradição e vivência no morro carioca”, que pode ser visualizado no canal Retrato Brasil, no portal da rede Brasilidade Solidária. 
Os moradores do Morro do Borel já receberam alguns grupos de turistas. O roteiro já foi realizado, inclusive, por um grupo de estudantes do curso de Geografia da Unicamp. No entanto, não estão conseguindo fazer o roteiro com certa regularidade.

Atualmente, alguns moradores do Morro estão trabalhando com proposta de ecoturismo no Parque Nacional da Tijuca. Desta vez, o roteiro está sendo pensado por moradores que fizeram o curso e outros que não fizeram. Um professor do Departamento de Turismo da UERJ que se interessou pela proposta está acompanhando essa ação.

O formato do trabalho no Borel talvez seja um exemplo de como manter um projeto ativo, mesmo quando pessoas que começaram o processo deixaram de participar. É um bom exemplo do funcionamento da rede como uma organização que, por meio da troca de informações e da solidariedade entre os membros, permite que o processo avance, sem que percamos a linha central, nesse caso, o turismo como um instrumento de reflexão crítica sobre a vida nas favelas cariocas.

A questão do reconhecimento ou não dos indivíduos, ou melhor, do sentimento de ser ou não reconhecidos no seio de um grupo volta novamente como eixo central das tentativas de tecer redes de colaboração para planejamento e organização do turismo e dela depende a "densidade da rede".

\section{Densidade da rede}

As densidades das relações sociais na rede variam quanto à intensidade dos encontros entre indivíduos, pois em alguns momentos conseguimos reunir um grande número de pessoas. No entanto, depois de certo tempo, as relações permaneceram fortes apenas entre um grupo reduzido de indivíduos.

Entretanto, vale ressaltar, que é muito difícil determinar o grau de influência da rede nos trabalhos cotidianos das pessoas ou nas instituições que pouco se relacionaram entre si.

A rede Brasilidade Solidária é mais uma aposta de trabalhos em redes do que uma rede consolidada com alto grau de regulação por meio de normas e "leis", apesar de ter nos "6Vs do turismo solidário" suas diretrizes de atuação (FORTUNATO; NEFFA, 2014).

As relações e os vínculos ocorrem de forma informal e espontânea, e a visibilidade dada aos "simpatizantes" da rede para os seus projetos, tanto por meio de matérias jornalísticas como por meio de documentários etnográficos, contribui para que se consolidem relações de confiança.

\section{Considerações: uma aposta na diversidade}

Os trabalhos da rede Brasilidade Solidária (www.brasilidadesolidaria.com.br) estão envoltos por uma gama de variáveis, o que torna a manutenção e o crescimento da rede uma tarefa complexa, pois nossos trabalhos cotidianos ocorrem com indivíduos e indivíduos estão sujeitos a alterações de humor, valores, ideologias, filosofia de vida, personalidade e crenças, portanto, é preciso uma grande atenção à questão do respeito à diversidade. 
Um dos principais pilares da rede é o trabalho com objetivos comuns, com um grupo que pensa de modo semelhante, mas semelhante não quer dizer igual e é justamente nos espaços de diversidade que se encontram os elementos capazes de proporcionar transformações significativas no interior de uma rede. Apostamos nos diálogos e nas convergências.

No trabalho em rede pretendemos construir novas formas de organização na sociedade contemporânea, pois tal modelo oferece certo grau de autonomia e emancipação aos indivíduos, na medida em que esses indivíduos trocam informações relevantes independentemente das instituições que possuem "maior poder" para realizar tais construções, como o Estado e o capital financeiro. As redes, portanto, podem ser pensadas como formas alternativas de organização popular a partir de novas lógicas. Santos (2002) faz referência a uma lógica do Sul, na qual poderíamos encontrar modos de vida que ofereçam um contraponto ao "status quo", apostando em uma lógica pautada na solidariedade e no reconhecimento recíproco.

No entanto, vale ressaltar que estamos imersos na cultura da reprodução do capital pautado no consumo, fato que produz relações humanas pautadas em objetos. Um modelo que "atrofia" tudo que é humano. Por outro lado, relações de dádiva aparecem como estruturantes do comportamento dos indivíduos em sociedade, nos quais se baseiam no dar-receber-retribuir (MOUSS, 1974).

Honneth (2003) traz a questão do reconhecimento recíproco e advoga a favor do reconhecimento segundo a legislação, no amor e na solidariedade. Temos, portanto, dois grandes campos distintos de interpretação da sociedade contemporânea: uma oferece mais impulsos para divisão; outro para aproximação. Em um quadro com tendência a divisão, promovemos a criação de redes entre iguais, fechadas ideológica e politicamente ao diálogo. Propomos redes abertas, pequenas redes, que se conectam a outras pequenas redes.

No quadro com tendências para o viver juntos, baseados em relações do tipo Eu-Tu e dialógicas (BUBER, 2001) existe uma possibilidade maior de pensarmos redes baseadas na diversidade e nas potencialidades dos encontros. Assim como nos apresenta Boaventura de Souza Santos (2000), que propõe um manifesto contra a experiência desperdiçada.

Redes de colaboração no campo do turismo podem oferecer aos destinos e produtos turísticos um grande diferencial no mercado, na medida em que confiam na importância do diálogo e dos encontros como oportunidades de inovação e constante aprendizado.

O resultado do trabalho em redes no campo do turismo apresenta uma sinergia advinda das conexões da rede. Criam-se elementos que emergem do encontro com a diversidade e que não poderiam se fazer presentes sem a conexão. Surge a inovação fruto da sinergia. A organização do todo possui qualidades ou propriedades novas em relação às partes isoladamente (MORIN, 2013).

As redes aproximam pessoas no campo e nas cidades, nos grandes centros urbanos e mantêm a utopia dos movimentos coletivos em permanente transformação. Acreditamos que os avanços na construção de redes estão intimamente relacionados à tentativa de tentar ceder menos ao impulso de nos diferenciarmos e mais aos nossos impulsos de vivermos juntos e nos reconhecermos no outro para compartilharmos nossa humanidade comum, em um caminho aberto e evolutivo. 


\section{Referências}

ACIOLI, S. Redes sociais e teoria social: revendo os fundamentos dos conceitos. Londrina, v. 12, n. esp., 2007.

BARNES, J. A. Redes sociais e processo político. In: FELDMAN-BIANCO, B. (Org.). Antropologia das sociedades contemporâneas. São Paulo: Global, 2010. p. 171-204.

BAUMAN, Z. Tempos líquidos. Rio de Janeiro: Jorge Zahar, 2007.

BRASIL. Ministério do Turismo. Coordenação Geral de Regionalização. Programa de Regionalização do Turismo - Roteiros do Brasil: formação de redes. Ministério do Turismo. Secretaria Nacional de Políticas de Turismo. Departamento de Estruturação, Articulação e Ordenamento Turístico. Coordenação Geral de Regionalização. Brasília, 55p. 2007.

BUBER, M. Eu e tu. São Paulo: Centauro, 2001.

CASTELLS, M. A Sociedade em Rede. A Era da Informática: economia, sociedade e cultura. Rio de Janeiro, Ed. Paz e Vida, 1999.

ELIAS, N. A sociedade dos indivíduos. Rio de Janeiro: Jorge Zahar, 1994.

FORTUNATO, R. A.; NEFFA, E. M. Abordagem Complexa e Desenvolvimento Local por meio do Turismo Solidário: o caso da rede "Brasilidade Solidária". Turismo em Análise, v. 25, n. 1, p. 51-74, 2014.

HONNETH, A. Luta por reconhecimento: a gramática moral dos conflitos sociais. São Paulo: Ed. 34, 2003.

LATour, B. Reagregando o Social. Bauru, SP: Edusc/Salvador, BA: EDUFBA, 2012.

MAFFESOLI, M. 0 tempo das tribos: o declínio do individualismo na sociedade de massa. Coleção Ensaio \& Teoria. Rio de Janeiro: Forense Universitária, 2. ed., 1998.

MAUSS, M. Ensaio sobre a dádiva. Forma e razão da troca nas sociedades arcaicas. In:

Sociologia e Antropologia, v. II. São Paulo: Edusp, 1974.

MORIN, E. Ciência com consciência. Rio de Janeiro: Bertrand Brasil, 2013.

MUSSO, P. A Filosofia da Rede. In: PARENTE, A. (Org.). Tramas da Rede: novas dimensões filosóficas, estéticas e políticas da comunicação. Editora Sulina, 1. ed., 2004.

REDE BRASILIDADE SOLIDÁRIA. Disponível em: 〈www.brasilidadesolidaria.com.br〉. Acesso em:11 nov. 2015.

SANTOS, B. S. A crítica da razão indolente: contra o desperdício da experiência. São Paulo: Cortez, 2000.

Para uma sociologia das ausências e das emergências. Revista Crítica de Ciências Sociais, 63, p. 237-280, 2002.

TOMAÉL, M. I; ALCARÁ, A. R; DI CHIARA, I. G. Das redes sociais à inovação. Ciência da Informação, Brasília, DF, v. 34, n. 2, p. 93-104, maio/ago, 2005. 